\title{
Factors associated with the availability of iodized salt at household level: a case study in Bangladesh
}

\author{
Jahidur Rahman Khan ${ }^{1, *}$, Raaj Kishore Biswas ${ }^{2}$, Md Tuhin Sheikh ${ }^{3,4}$ and Molla Huq ${ }^{5}$ \\ ${ }^{1}$ Centre for Research and Action in Public Health, Health Research Institute, Faculty of Health, University of Canberra, \\ Room \# 22, 11 Kirinari Street, Bruce, Canberra, ACT 2617, Australia: ${ }^{2}$ Transport and Road Safety (TARS) Research, \\ University of New South Wales, Sydney, New South Wales, Australia: ${ }^{3}$ Institute of Statistical Research and Training, \\ University of Dhaka, Dhaka, Bangladesh: ${ }^{4}$ Department of Statistics, University of Connecticut, Storrs, CT, USA: \\ ${ }^{5}$ Department of Medicine, The University of Melbourne, Melbourne, Victoria, Australia
}

Submitted 9 January 2018: Final revision received 28 October 2018: Accepted 23 November 2018: First published online 13 February 2019

\begin{abstract}
Objective: The availability of iodized salt in households remains low in Bangladesh, which calls for improving the salt iodization quality and its coverage. The present study assessed the socio-economic disparity in Bangladesh to characterize the availability of iodized salt at household level.

Design: Associations between different socio-economic factors and availability of iodized salt at household level were explored using Bayesian mixed-effects logistic models after adjusting the district- and cluster-level random effects.

Setting: Bangladesh Multiple Indicator Cluster Survey (MICS), 2012-13.

Participants: Households (sample size, $n$ 50 981).

Results: Results showed that $73 \cdot 15 \%$ of household salt samples were iodized to some extent although iodization level varied. According to the regression model, houses with young (adjusted odds ratio of posterior mean (OR) $=1 \cdot 31 ; 95 \%$ credible interval (CI) 1.09, 1.64) and educated (OR $=3 \cdot 66 ; 95 \%$ CI 3.25, 4.23) household heads had significantly higher likelihood of availability of iodized salt. In addition, iodized salt was less likely be found in poor and rural households, as urban households were $2 \cdot 88$ times (95\% CI $2 \cdot 41,3 \cdot 34)$ more likely have iodized salt. Moreover, the regional locations of the households were an important component that contributed to the local iodized salt coverage. As per the districtwise distribution, the north-west part of Bangladesh and Cox's Bazar in the far south seemed to lack household-level iodized salt.

Conclusions: Our findings suggest that iodized salt intervention should be promoted considering the area variations, which could potentially help policy makers to design interventions in the context of Bangladesh.
\end{abstract}

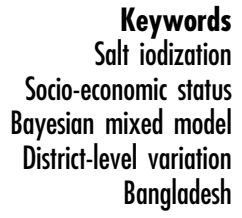

Keywords Socio-economic status Bayesian mixed model Bangladesh
Iodine is an essential micronutrient that is required for the synthesis of thyroid hormone. The deficiency of iodine leads to thyroid dysfunction as the thyroid gland cannot produce sufficient amounts of thyroid hormone ${ }^{(1-3)}$, which causes poor physical growth, cognitive impairment, neuro-behavioural and intellectual disorders, and CVD ${ }^{(4,5)}$. Moreover, iodine deficiency also increases the risk of reproductive failure (such as miscarriage, premature birth and stillbirth) among pregnant women ${ }^{(6)}$. According to the 2013 Lancet series on maternal and child nutrition, 28.5\% of the world's population was iodine deficient ${ }^{(7,8)}$. The WHO estimates showed that about 50 million people had some degree of mental impairment caused by iodine deficiency $^{(9)}$. The 2013 UNICEF report showed that about 35 million newborns were unprotected from the lifelong consequences of iodine-deficiency disorders (IDD) globally $^{(10)}$. Among them, sub-Saharan Africa had the highest number of unprotected newborns (about 14 million) followed by South Asia (with 11 million) ${ }^{(10)}$. In Bangladesh, the last IDD survey (from 2004-05) showed that the prevalence of IDD (as indicated by urinary iodine concentration below $100 \mu \mathrm{g} / \mathrm{l}$ ) among children and women of reproductive age (15-49 years) was 34 and $39 \%$, respectively ${ }^{(11)}$. The prevalence of IDD was 40 and $42 \%$ in school-age children and women, respectively, in the Bangladesh National Micronutrients Status Survey 2011-12 $2^{(12)}$. Although the rate of IDD has been decreasing over the years, the issue of IDD still persists at a magnitude of public health significance nuisance in developing countries such as Bangladesh ${ }^{(11,13,14)}$. One possible approach to control this problem is to improve iodine status by universal salt iodization, which has been the 
most widely used strategy to control and eliminate IDD for the last 30 years ${ }^{(10,14)}$. Although many countries passed legislation on universal salt iodization (expecting more than $90 \%$ of households to have access to adequately iodized salt containing $15-40 \mathrm{ppm}$ of iodine $)^{(14,15)}$, the overall percentage of households (worldwide) with access to iodized salt is still unsatisfactory. For instance, as of 2013, only $75 \%$ of all households worldwide had access to adequately iodized salt, and this was $69 \%$ in South Asia ${ }^{(10)}$.

In Bangladesh, a South Asian country, the status of iodine coverage is not encouraging. National household surveys have shown that the use of iodized salt ( $\geq 5 \mathrm{ppm}$ ) and adequately iodized salt $(\geq 15 \mathrm{ppm})$ changed from $81.0 \%$ (in 2004-05) to $80.3 \%$ (in 2011-12) and $72.6 \%$ (in 2012-13) for iodized salt, and from $51.0 \%$ (in 2004-05) to $57.0 \%$ (in 2011-12) and 54.3\% (in 2012-13) for adequately iodized salt ${ }^{(11,12,16)}$. The most recent Bangladesh National Salt Iodization Survey (NSIS) of 2015 showed that only $50.5 \%$ households in Bangladesh have access to adequately iodized salt, whereas only $65.0 \%$ households have access to iodized salt ${ }^{(17)}$. Although the scenario has not changed much in adequate iodized salt coverage, there is a notable decrease in level of some iodized salt coverage over the years, which is alarming ${ }^{(17)}$.

There have been a limited number of studies which investigated the availability of iodized salt among households in Bangladesh ${ }^{(11,17,18)}$. To best of our knowledge, no study has investigated the relationship between household socio-economic status (SES) and availability of iodized salt in Bangladesh using a nationwide survey. According to the Bangladesh Multiple Indicator Cluster Survey (MICS) 2012-13 ${ }^{(16)}, 27 \%$ of households in Bangladesh have no iodine content in their salt, which invites more studies to be conducted in this area, particularly in identifying the vulnerable households.

Household SES in Bangladesh largely depends on the head of the household ${ }^{(19-21)}$, who makes most of the household financial decisions ${ }^{(22)}$. It is an important variable collected for household surveys like the Bangladesh Demographic and Health Surveys ${ }^{(23)}$, where mostly heads of households are male and Muslim ${ }^{(24,25)}$. The traditional provider of salt is the household head ${ }^{(26)}$, and that is why in most intervention studies of iodine deficiency, the head is given the iodized salt to ensure proper distribution ${ }^{(27-29)}$.

The World Bank suggests that the governments of lowand middle-income countries need to put a high priority on salt iodization to promote sustainable health and economic development ${ }^{(30)}$. It is expected that people in the higher wealth quantiles are more aware of iodized salt compared with the poorer households ${ }^{(31,32)}$. Similarly, improved iodine status is generally observed in urban areas compared with rural areas, where goitre is more prevalent ${ }^{(33-36)}$, although exceptions do exist ${ }^{(37)}$. Geographical divisions along with inequality are also expected to be differentiating factors for household coverage of iodized salt ${ }^{(25)}$.
The present study intended to explore the context of household-level availability of iodized salt in Bangladesh by analysing national survey data. The current paper assesses the determinants of the availability of iodized salt at household level in Bangladesh by considering household SES, demographic factors and geographic location using Bayesian mixed-effect logistic regression models. Such study will help policy makers to design intervention strategies for households in the context of Bangladesh.

\section{Methods}

\section{Sampling}

The data for the present study were extracted from the most recent Bangladesh MICS of 2012-13 ${ }^{(38)}$. This survey aimed to attain national-level estimates for various health indicators of the seven divisions and sixty-four districts in Bangladesh, where a two-stage stratified cluster sampling design was used. The districts were identified as the primary sampling strata and a specific number of census enumeration areas were selected systematically using probability-proportional-to-size sampling within each stratum. After completing the household listing within the selected enumeration areas, a systematic sample of twenty households was drawn from each enumeration area. All surveyed households were requested to provide a sample of their cooking salt, which was used to test the adequate proportion of iodine. It was tested using salt test kits and the presence of potassium iodate content was quantified $^{(18)}$. In the present study, we selected only those households that had results of the salt test as well as complete information on all selected covariates. A small proportion of households (about 1.1\%) had no available salt in their households during the survey ${ }^{(16)}$, which were excluded from our analysis. The final sample size for the present study was 50981 .

\section{Variables}

Outcome variable

The outcome variable 'availability of household-level iodized salt in Bangladesh' was categorized into two scales: iodized salt (if household salt had $>0$ ppm iodine) and non-iodized salt (if household salt had 0 ppm iodine). Thus, the households were divided into two groups: households with iodized salt $v$. non-iodized salt.

\section{Selected covariates}

The household SES variables that were expected to be associated with the availability of iodized salt in the households were: wealth index ('poor', 'middle', 'rich'), age of the household head (' $<25$ ', '25-34', '35-44', ' $45-54$ ', '55-64' and ' $\geq 65$ ' years), sex of the household head ('female', 'male'), education of the household head ('no education', 'primary incomplete', 'primary complete', 
'secondary incomplete', 'secondary complete or higher'), religion of the household head ('Muslim', 'others'), place of residence ('rural', 'urban') and division (which is largest local government administrative area in Bangladesh; 'Barisal', 'Chittagong', 'Dhaka', 'Khulna', 'Rajshahi', 'Rangpur', 'Sylhet'). The household wealth index was precalculated in the data based on asset variables and using principal component analysis ${ }^{(18)}$.

\section{Statistical analysis}

Bivariate and multivariable statistical analyses were performed in the present study. Initially, the bivariate associations between the availability of iodized salt at household level and the selected SES variables were tested using the $\chi^{2}$ test. Then, mixed-effects binary logistic regression analysis was performed to examine the significance of the associated factors with the householdlevel availability of iodized salt. We applied the Bayesian framework with the Markov chain Monte Carlo (MCMC) algorithm instead of classical maximum likelihood procedures to attain the unbiased estimates of both variance components and predictors ${ }^{(39)}$.

Bayesian analyses require 'prior' distributions for all parameters. We used parameter expanded priors which were approximately flat (but still proper) for the $\mathrm{SD}^{(40)}$. Inspection of the trace and density plots and effective sample size indicated convergence of models. We ran the models for 100000 iterations with a burn-in (the number of initial iterations discarded) of 20000 and a thinning (the number of saved estimates for analysis) interval of 500 to achieve low autocorrelation between recorded iterations. Three models were fitted to examine the impact of different predictors on the binary outcome and importance of the random effects. First, we fitted a random-intercept model with district-level variation of the outcome; second, a random-intercept model to assess the cluster-level variation; and finally, a two-level random-intercept model to evaluate the district- and cluster-level variation. The deviance information criterion determined the fitness of the models. All statistical analyses were performed in $\mathrm{R}$ version 3.3.0. We used MCMCglmm package in $\mathrm{R}$ for Bayesian models, which has previously been applied in health- and nutrition-related studies ${ }^{(41-43)}$. The adjusted odds ratio of posterior mean (OR) in favour with its $95 \%$ credible interval (CI) were computed for the coefficient of each of the covariates. The Bayesian $P$ value $\left(P_{\mathrm{MCMC}}\right)$ was calculated to indicate the statistical significance of the variables.

\section{Results}

Among the selected sample of 50981 households, $73 \cdot 15 \%$ had some level of iodine in the salt sample they provided during the survey period (data not shown). Table 1 displays the bivariate analyses that show the outcome of iodized salt consumption in the households of various SES. The availability of iodized salt at the household level varied significantly $(P<0.001)$ across the different wealth groups. From Table 1 we can see that only $62.67 \%$ of households from the poor wealth class had iodine in their household salt sample, which was almost 25 percentage points lower than for the rich. The proportion of households who had some level of iodized salt coverage varied among households with female and male heads, being 76.51 and $72.82 \%$, respectively. The proportion of iodized salt availability in households did not show much variation with age of the household head, as availability was about $71-75 \%$ for every group. The availability of iodized salt in households varied significantly $(P<0.001)$ across the different educational groups of household heads. Household heads with secondary or higher education had higher coverage of iodized salt in their households (89.36\%) compared with non-educated household heads (63.86\%). In addition, household coverage of iodized salt in urban areas was 16 percentage points higher compared with rural areas. Barisal division had the highest householdlevel availability of iodized salt, whereas the lowest was in the north-west part of Bangladesh (Rangpur and Rajshahi).

The district-level variation in the availability of iodized salt in households was apparent in Bangladesh as depicted in Fig. 1. Particularly the north-west part of Bangladesh lacked household-level iodized salt. However, the worst condition persisted in Cox's Bazar, the only district where the household-level iodized salt coverage was below 25\%, followed by Chapai Nawabganj and Thakurgaon. The middle and southern part of the country, including Dhaka (the capital), Khulna and their adjacent areas showed higher coverage of iodized salt in households.

Table 2 summarizes the association of different factors with household-level availability of iodized salt. The three Bayesian mixed models with different random effects showed consistent results. However, the third model with the lowest deviance information criterion was the bestfitted model, where the variation of both districts and clusters was adjusted for. The random variances in all models were significant, which justifies the application of mixed-effect models. In addition, the estimates of variance parameters differed significantly from zero, indicating that the unmeasured and unobserved factors shared by community and districts had an association with householdlevel iodized salt coverage in Bangladesh. Education, religion and sex of the household head, along with household wealth, residence and geographical division, were significantly associated with availability of household iodized salt in Bangladesh.

The economic status of the households showed a significant association with the household availability of iodized salt. Especially, the middle and rich classes were 1.84 (95\% CI 1.69, 1.98; $\left.P_{\mathrm{MCMC}}<0.01\right)$ and 4.09 (95\% CI $\left.3.65,4.47 ; P_{\text {MCMC }}<0.01\right)$ times more likely to use iodized salt, respectively, compared with the poor (Model 3, 
Table 1 Bivariate analysis of the association of household-level iodized salt coverage in Bangladesh with household socio-economic status, 2012-13

\begin{tabular}{|c|c|c|c|}
\hline Variable & $\begin{array}{c}\text { Sample size } \\
(\text { (n 50981) }\end{array}$ & $\begin{array}{l}\text { Household with } \\
\text { iodized salt (\%) }\end{array}$ & $\begin{array}{l}P \text { value } \\
\left(x^{2} \text { test }\right)\end{array}$ \\
\hline \multicolumn{4}{|l|}{ Wealth index } \\
\hline Poor & 24496 & 62.67 & \multirow[t]{3}{*}{$<0.001$} \\
\hline Middle & 9988 & 74.08 & \\
\hline Rich & 16497 & 88.14 & \\
\hline \multicolumn{4}{|l|}{ Age of household head (years) } \\
\hline$<25$ & 1587 & 71.46 & \multirow[t]{6}{*}{$<0.001$} \\
\hline $25-34$ & 9801 & 74.73 & \\
\hline $35-44$ & 13216 & 73.90 & \\
\hline $45-54$ & 11128 & $72 \cdot 37$ & \\
\hline $55-64$ & 8411 & $72 \cdot 64$ & \\
\hline$\geq 65$ & 6838 & $71 \cdot 73$ & \\
\hline \multicolumn{4}{|l|}{ Sex of household head } \\
\hline Female & 4563 & $76 \cdot 51$ & \multirow[t]{2}{*}{$<0.001$} \\
\hline Male & 46418 & $72 \cdot 82$ & \\
\hline \multicolumn{4}{|l|}{ Education of household head } \\
\hline No education & 22216 & 63.86 & \multirow[t]{5}{*}{$<0.001$} \\
\hline Primary incomplete & 7224 & 73.82 & \\
\hline Primary complete & 5803 & 75.94 & \\
\hline Secondary incomplete & 8653 & $81 \cdot 28$ & \\
\hline Secondary complete or higher & 7085 & $89 \cdot 36$ & \\
\hline \multicolumn{4}{|l|}{ Religion of household head } \\
\hline Muslim & 44380 & 71.68 & \multirow[t]{2}{*}{$<0.001$} \\
\hline Others & 6601 & 83.05 & \\
\hline \multicolumn{4}{|l|}{ Place of residence } \\
\hline Rural & 42696 & $70 \cdot 54$ & \multirow[t]{2}{*}{$<0.001$} \\
\hline Urban & 8285 & $86 \cdot 60$ & \\
\hline \multicolumn{4}{|l|}{ Division } \\
\hline Barisal & 5107 & 88.04 & \multirow[t]{7}{*}{$<0.001$} \\
\hline Chittagong & 8935 & 79.05 & \\
\hline Dhaka & 12661 & 74.50 & \\
\hline Khulna & 8039 & 84.76 & \\
\hline Rajshahi & 6132 & $55 \cdot 51$ & \\
\hline Rangpur & 6626 & 51.65 & \\
\hline Sylhet & 3481 & $76 \cdot 41$ & \\
\hline
\end{tabular}

Table 2). Availability of iodized salt in households with younger heads $(25-34$ years) was found to be significantly higher $(31 \%$ more) than in households with the youngest heads ( $<25$ years). Surprisingly, households had $23 \%\left(P_{\mathrm{MCMC}}<0.01\right)$ less chance of using iodized salt under a male head compared with a female head, although only $9 \%$ households had a female head in the sample. The odds of availability of iodized salt at household level increased significantly with education level (primary complete, primary incomplete, secondary complete or higher, secondary incomplete) by 1.25, 1.57, 1.89 and 3.66 times, respectively, compared with households where the head had no education. Religion of households was found to have significant $\left(P_{\text {MCMC }}<0 \cdot 01\right)$ association with household-level access to iodized salt; in particular, households with other religious believers had $47 \%$ higher likelihood of using iodized salt compared with Muslim households. Significantly higher consumption $(\mathrm{OR}=2 \cdot 88$; 95\% CI 2.41, 3.34; $\left.P_{\mathrm{MCMC}}<0.01\right)$ of iodized salt was observed in urban respondents compared with rural counterparts. The coverage gap between Barisal (reference) and Rangpur or Barisal and Rajshahi divisions was significant in all three models, where locals of Rajshahi and Rangpur had lesser iodized salt availability at households. The significant cluster- (1.69) and districtlevel $(2 \cdot 12)$ variances reveal that the likelihoods of the availability of household iodized salt at these levels were correlated, which indicated that there were other factors associated with iodized salt coverage at community and district level not explained by the observed covariates included in the models. This result further suggested that unobservable factors related to the districts were more likely to be associated with a higher likelihood of household iodized salt availability than the cluster-level unobservable factors.

Convergence diagnostic tests were used to assess the convergence of the Markov chain as explained in the 'Methods' section. Trace plots and density plots for the parameters of the posterior distribution obtained by the MCMC algorithm are presented in the online supplementary material (Supplemental Figs 1-6). None of the trace plots displayed any significant upward or downward trend along the iterations, and the density plots showed almost symmetrical distributions. In particular, the trace plots exhibited the so-called 'thick pen', which indicated insignificant deviations from stationarity and that the MCMC algorithm could be considered as converged. 


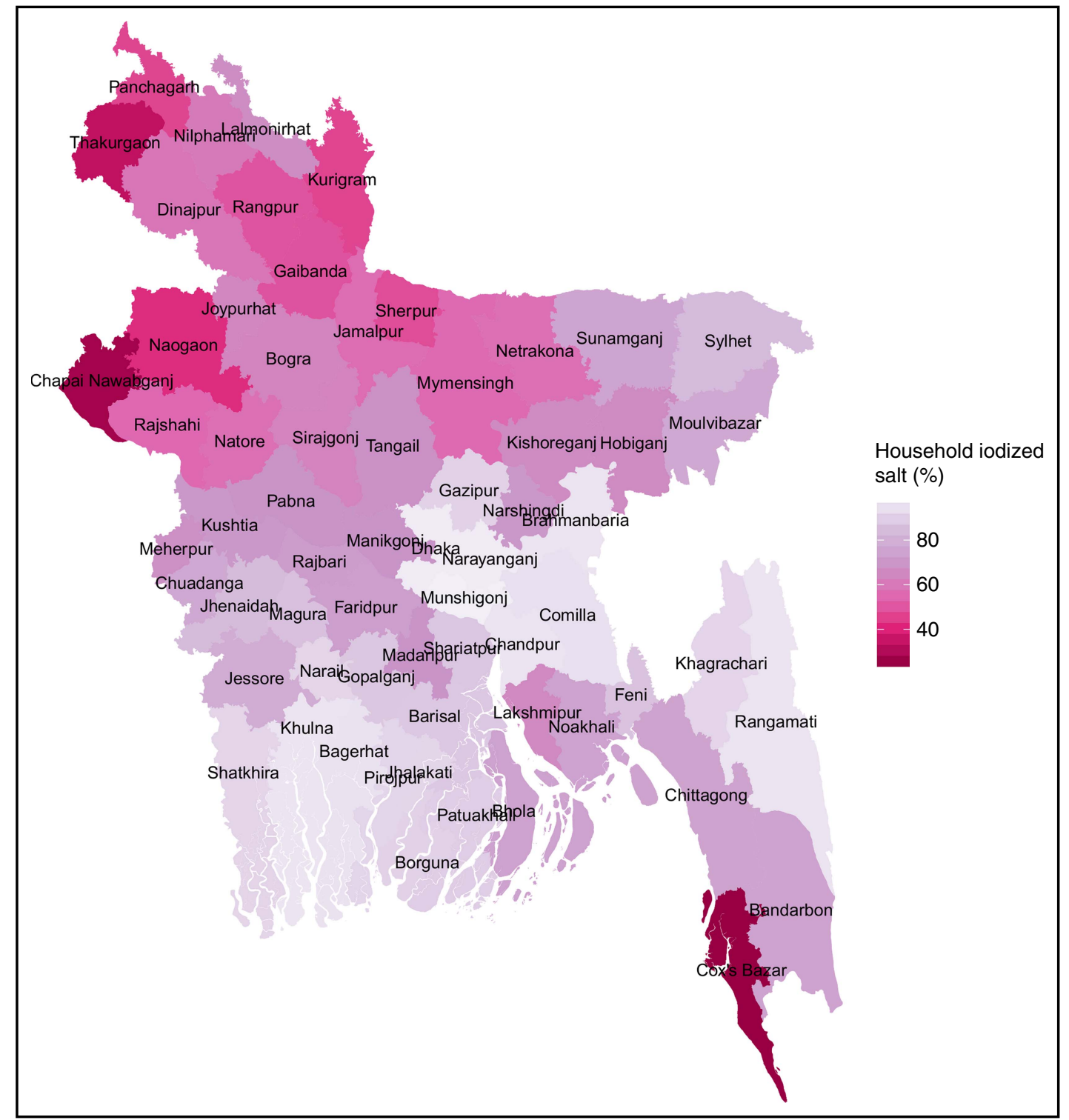

Fig. 1 (colour online) District-wise variation in the household-level iodized salt coverage in Bangladesh, 2012-13

\section{Discussion}

The present study determined the relationships between iodized salt availability and different socio-economic factors of households in Bangladesh. We analysed the Bangladesh MICS data of 2012-13 by using Bayesian mixed-effects logistic regression, which revealed some important results that require more attention from policy makers. The study found that household-level iodized salt availability was significantly associated with age of the household head and their education status. In addition, a significant inequality in household-level iodized salt availability was noticed due to family income status as well as their place of residence. The study also observed that the availability of iodized salt in households varied considerably between geographic locations, such as districts of Bangladesh.
Only $20 \%$ of the global population had access to iodized salt in 1990 and it rose to $71 \%$ in 2012; however, the longterm commitment from governments in different countries remains debatable ${ }^{(44)}$. The worrying signs are worse for developing nations due to the rise in IDD ${ }^{(45)}$. For example, a longitudinal study conducted in Bangladesh concluded that urinary iodine concentration during pregnancy depends on women's education and SES along with other factors ${ }^{(46)}$. Similarly, another study in Cox's Bazar showed that iodized salt is considered a sign of prestige in the local community as it demonstrated wealth and education ${ }^{(47)}$. Furthermore, women seem to exert higher responsibility regarding household decisions (e.g. one of the findings of our study was that female household heads were more concerned regarding iodized salt than males), which is why microcredits are highly concentrated on female borrowers in Bangladesh $^{(48,49)}$. It could also be contributed to by the fact 
Table 2 The Bayesian mixed-effects logistic regression models fitted to the association of household-level iodized salt coverage in Bangladesh with household socio-economic status, 2012-13

\begin{tabular}{|c|c|c|c|c|c|c|c|c|c|}
\hline \multirow[b]{2}{*}{ Variable } & \multicolumn{3}{|c|}{$\begin{array}{l}\text { Model 1: Bayesian logistic with } \\
\text { district random effect }\end{array}$} & \multicolumn{3}{|c|}{$\begin{array}{l}\text { Model 2: Bayesian logistic with } \\
\text { cluster random effect }\end{array}$} & \multicolumn{3}{|c|}{$\begin{array}{l}\text { Model 3: Bayesian logistic with district and } \\
\text { cluster random effects }\end{array}$} \\
\hline & OR & $95 \% \mathrm{Cl}$ & $P_{\mathrm{MCMC}}$ & OR & $95 \% \mathrm{Cl}$ & $P_{\mathrm{MCMC}}$ & OR & $95 \% \mathrm{Cl}$ & $P_{\mathrm{MCMC}}$ \\
\hline \multicolumn{10}{|l|}{ Wealth index (ref.: Poor) } \\
\hline Middle & 1.76 & $1.65,1.89$ & $<0.01$ & 1.72 & $1.59,1.88$ & $<0.01$ & 1.84 & $1.69,1.98$ & $<0.01$ \\
\hline Rich & 3.68 & $3.42,3.98$ & $<0.01$ & 3.58 & $3.32,4.00$ & $<0.01$ & 4.09 & $3.65,4.47$ & $<0.01$ \\
\hline \multicolumn{10}{|c|}{ Age of household head (years) (ref.: <25) } \\
\hline $25-34$ & 1.25 & $1.07,1.43$ & $<0.01$ & 1.24 & $1.05,1.47$ & 0.013 & 1.31 & $1.09,1.64$ & $<0.01$ \\
\hline $35-44$ & 1.08 & $0.94,1.25$ & 0.375 & 1.09 & $0.94,1.32$ & 0.288 & $1 \cdot 12$ & $0.88,1.34$ & 0.263 \\
\hline $45-54$ & 0.96 & $0.81,1 \cdot 11$ & 0.625 & 0.96 & $0.82,1.14$ & 0.638 & 0.97 & $0.80,1.22$ & 0.863 \\
\hline $55-64$ & 0.91 & $0.79,1.07$ & 0.288 & 0.93 & $0.77,1 \cdot 10$ & 0.450 & 0.93 & $0.73,1.12$ & 0.513 \\
\hline$\geq 65$ & 0.90 & $0.75,1.07$ & 0.263 & 0.92 & $0.77,1.12$ & 0.350 & 0.92 & $0.74,1.11$ & 0.388 \\
\hline \multicolumn{10}{|l|}{ Sex of household head (ref.: Female) } \\
\hline \multicolumn{7}{|l|}{ Education household head (ref.: No) } & 0.77 & $0.68,0.85$ & $<0.01$ \\
\hline Primary incomplete & $1 \cdot 22$ & $1 \cdot 13,1.32$ & $<0.01$ & 1.25 & $1 \cdot 15,1 \cdot 36$ & $<0.01$ & 1.25 & $1.14,1.35$ & $<0.01$ \\
\hline Primary complete & 1.46 & $1.35,1.60$ & $<0.01$ & 1.53 & $1.39,1.69$ & $<0.01$ & 1.57 & $1.41,1.75$ & $<0.01$ \\
\hline Secondary incomplete & 1.68 & $1.55,1.81$ & $<0.01$ & 1.80 & $1.65,1.96$ & $<0.01$ & 1.89 & $1 \cdot 75,2 \cdot 12$ & $<0.01$ \\
\hline Secondary complete or higher & 2.89 & $2 \cdot 62,3 \cdot 21$ & $<0.01$ & $3 \cdot 17$ & $2 \cdot 80,3.56$ & $<0.01$ & 3.66 & $3 \cdot 25,4 \cdot 23$ & $<0.01$ \\
\hline \multicolumn{10}{|c|}{ Religion of household head (ref.: Muslim) } \\
\hline $\begin{array}{l}\text { Others } \\
\text { Place of residence (ref } \cdot \text { Rural) }\end{array}$ & 1.66 & $1.52,1.85$ & $<0.01$ & 1.61 & $1.44,1.88$ & $<0.01$ & 1.47 & $1 \cdot 30,1 \cdot 73$ & $<0.01$ \\
\hline \multicolumn{10}{|l|}{ Place of residence (ref.: Rural) } \\
\hline Urban & $2 \cdot 21$ & $2 \cdot 01,2 \cdot 40$ & $<0.01$ & $2 \cdot 78$ & $2 \cdot 22,3.33$ & $<0.01$ & 2.88 & $2.41,3.34$ & $<0.01$ \\
\hline \multicolumn{10}{|l|}{ Division (ref.: Barisal) } \\
\hline Chittagong & 0.49 & $0.18,1.52$ & 0.213 & 0.35 & $0.27,0.45$ & $<0.01$ & 0.48 & $0.12,1.92$ & 0.313 \\
\hline Dhaka & 0.36 & $0.15,1.08$ & $<0.01$ & 0.22 & $0.17,0.28$ & $<0.01$ & $0 \cdot 30$ & $0.08,1.14$ & 0.088 \\
\hline Khulna & 0.62 & $0.23,2.01$ & 0.425 & 0.56 & $0.44,0.76$ & $<0.01$ & 0.65 & $0.13,2.47$ & 0.613 \\
\hline Rajshahi & 0.08 & $0.03,0.20$ & $<0.01$ & 0.06 & $0.04,0.08$ & $<0.01$ & 0.05 & $0.01,0.20$ & $<0.01$ \\
\hline Rangpur & 0.08 & $0.02,0.22$ & $<0.01$ & 0.05 & $0.04,0.07$ & $<0.01$ & 0.04 & $0.01,0.20$ & $<0.01$ \\
\hline Sylhet & 0.33 & $0.07,1.44$ & 0.075 & 0.25 & $0.19,0.34$ & $<0.01$ & 0.26 & $0.06,1.87$ & 0.175 \\
\hline \multicolumn{10}{|l|}{ Variance of random effect } \\
\hline District-level variation & 1.48 & $0.95,2.05$ & & & & & $2 \cdot 12$ & $1.34,2.95$ & \\
\hline Cluster-level variation & & & & $2 \cdot 61$ & $2 \cdot 42,2 \cdot 82$ & & 1.69 & $1.54,1.83$ & \\
\hline DIC & & 45788 & & & 41876 & & & 40742 & \\
\hline
\end{tabular}

$\mathrm{OR}$, adjusted odds ratio of posterior mean; $\mathrm{Cl}$, credible interval; $P_{\mathrm{MCMC}}$, Bayesian $P$ value; ref., reference category; DIC, deviance information criterion. 
that traditionally females prepare the food for the family in Bangladesh and they tend to be more concerned regarding nutrition ${ }^{(50)}$. We reached a homogeneous conclusion with the literature that several household SES variables are associated with household-level iodized salt availability or consumption of iodized salt all over Bangladesh ${ }^{(17)}$.

Households' access to adequately iodized salt is commonly dependent on several factors such awareness, price, convenience, utilization preferences, packaging and availability ${ }^{(17)}$. Differences in adequately iodized salt availability in households reported here by SES could be the result of these factors. Moreover, a recent survey in Bangladesh showed that poor households were almost twice as likely to use open salt (unbranded salt without any form of packaging) and more likely to source salt from non-formal retail channels such as the point of production $^{(12,17)}$. Agreeing with these, we found that people with higher SES (higher wealth index and better educational status of household head) were more likely to purchase iodized salt rather than salt lacking proper quality of iodine. The survey considered in the present study lacked data on micro-level awareness, price of salt, convenience of location, utilization preferences, packaging or availability in the local market, which could solicit further investigations on this phenomenon in Bangladesh.

The poor and the illiterate living in the rural areas were the most vulnerable for iodine deficiency. This was an expected outcome as economically challenged households cannot afford to spend extra money to buy the slightly costlier iodized salt ${ }^{(51,52)}$, which is a common scenario in Africa and South Asia ${ }^{(53,54)}$. The lack of awareness creates a knowledge gap for these sections of households, and they become victims of IDD ${ }^{(55,56)}$. The rural areas suffer from the same problem due to the lower economic status and the shortage of awareness campaigns or lack of information ${ }^{(14)}$. This is visible in Fig. 1, where the divisional cities have higher coverage than other areas of Bangladesh. Myths like 'Iodine is contained in the sea fish that we eat, so we don't have to eat iodized salt' persist due to illiteracy and lack of awareness ${ }^{(57)}$.

The purchasing capacity of the locals and lack of government monitoring allow salt production to be unmonitored, cheap and irresponsible. Although iodizing salt does not cost a lot, salt mills operate on slim profit margins in Bangladesh and they tend to avoid the iodizing procedure $^{(57)}$. A study of 121 salt factories in four districts of Bangladesh found that none of the factories maintained adequate iodizing quantity, with most mills adding less than the required amount ${ }^{(58)}$. It was also found that carelessness of the packaging process compromises the content of iodine. A survey report prepared by International Diarrhoeal Disease Research, Bangladesh (icddr,b) found that the household coverage for adequately iodized salt has decreased (non-significantly) to about $51 \%$ since $2011^{(17)}$. The survey found that $80 \%$ of the open salt in the sample had no iodine $(<5 \mathrm{ppm})$; and the weak salt law as well as the lack of clear guidance on enforcement of the regulations for violating it could be potential reasons for such a scenario. The law was introduced in 1989 and modified in $2013^{(16)}$. However, the lack of awareness campaigns is making it difficult for people in the most vulnerable parts of the community to have access to iodized salt, leading to IDD.

The unavailability of iodized salt in the remote regions coupled with households' lack of purchasing power potentially explains the unsatisfactory scenario of iodized salt in Bangladesh. In the icddr,b survey ${ }^{(17)}$, the quantity of open salt sold in rural areas was twice the amount in urban areas. It attracts the poor people residing in rural areas to go for the cheaper option. Furthermore, rural residents in Bangladesh are comparatively poorer than urban residents ${ }^{(59)}$, which integrates with the lack of general awareness or education and leads them to consume lowquality salt. This encourages the quality producers to stay in the urban market, where most consumers can afford it. Proper utilization of the salt law, greater availability of quality product at a reasonable price and extensive awareness campaigns should contribute to this context.

\section{Limitation of the study}

In the present study, availability of iodized salt was assessed through household salt primarily used during food preparation or as table salt; however, it did not account for potentially iodized salt consumed through processed foods. Consumption of processed foods is higher in urban areas, which means that urban residents have greater scope for intake of iodine through this salt (such as in ready meals, processed meats, cheese, salty snack foods, instant noodles, etc.), and processed foods are also consumed more frequently in large amounts (such as bread and processed cereal products) ${ }^{(60)}$. This creates a direct contrast between urban and rural diets that might affect the iodine consumption rate among various locations and act as a confounding factor in the fitted models. However, the secondary data set analysed in the present study lacks specific information on general awareness, price, convenience, utilization preferences, packaging or availability, which could potentially have some effects on iodized salt coverage in households. Future studies, with further data collection, could investigate the association between price of the salt and its affordability by the general population.

\section{Conclusion}

Bangladesh has recently been promoted to a low-middleincome country; however, socio-economic disparity is still evident, especially in the public health sector. Approximately $50 \%$ of households in Bangladesh lack adequately iodized salt. The present study assessed the impact of household SES on some level of iodized salt using a national survey of about 50000 households. The Bayesian mixed-effect logistic model showed that after controlling 
for relevant variables, households' education, wealth index and location are important components that contribute to the local household-level iodized salt coverage in Bangladesh. The north-west part of the country and Cox's Bazar in the far south severely lack household iodized salt. The difference between rural and urban areas also suggests that the availability of iodized salt and the purchasing capacity of households are causing severe disparity in iodized salt availability. The salt law and clear guidance on enforcement of its regulations, along with local awareness campaigns, could improve the situation. Possible interventions regarding salt iodization should be conducted considering the district-level variations.

\section{Acknowledgements}

Acknowledgements: The authors would like to acknowledge UNICEF and the Bangladesh Bureau of Statistics (BBS) who conducted a nationwide survey and made their data available and freely accessible. The authors also thank anonymous reviewers and the editors for their insightful suggestions that helped develop the quality of the manuscript. Financial support: This research received no specific grant from any funding agency in the public, commercial or not-for-profit sectors. Conflict of interest: The authors declare that they have no competing interests. Authorship: J.R.K. conceptualized the study, compiled the data, synthesized the analysis plan, performed formal analyses, interpreted the outcomes and participated in critical review of the manuscript. R.K.B. helped to conceptualize the analysis plan, performed the geographical mapping, interpreted the findings and drafted the manuscript. The manuscript was critically reviewed and edited by M.T.S. and M.H. All authors helped to write the manuscript. Ethics of buman subject participation: Not applicable.

\section{Supplementary material}

To view supplementary material for this article, please visit https://doi.org/10.1017/S1368980018003907

\section{References}

1. Azizi F, Sheikholeslam R, Hedayati M et al. (2002) Sustainable control of iodine deficiency in Iran: beneficial results of the implementation of the mandatory law on salt iodization. J Endocrinol Invest 25, 409-413.

2. Zimmermann MB, Jooste PL, Pandav CS et al. (2008) Iodinedeficiency disorders. Lancet 372, 1251-1262.

3. Huang CJ, Tseng CL, Chen HS et al. (2016) Iodine nutritional status of school children in Nauru 2015. Nutrients 8, E520.

4. Moleti M, Lo Presti VP, Campolo MC et al. (2008) Iodine prophylaxis using iodized salt and risk of maternal thyroid failure in conditions of mild iodine deficiency. J Clin Endocrinol Metab 93, 2616-2621.

5. Andersson M, de Benoist B \& Rogers L (2010) Epidemiology of iodine deficiency: salt iodisation and iodine status. Best Pract Res Clin Endocrinol Metab 24, 1-11.

6. Dillon J \& Milliez J (2000) Reproductive failure in women living in iodine deficient areas of West Africa. BJOG 107, 631-636.

7. Institute of Public Health Nutrition (2015) National Strategy on Prevention and Control of Micronutrient Deficiencies, Bangladesh (2015-2024). Dhaka: Institute of Public Health Nutrition, Ministry of Health and Family Welfare, Government of the People's Republic of Bangladesh.

8. Black RE, Victora CG, Walker SP et al. (2013) Maternal and child undernutrition and overweight in low-income and middle-income countries. Lancet 382, 427-451.

9. Feyrer J, Politi D \& Weil DN (2017) The cognitive effects of micronutrient deficiency: evidence from salt iodization in the United States. J Eur Econ Assoc 15, 355-387.

10. UNICEF (2017) UNICEF Data: Monitoring the situation of children and women. https://data.unicef.org/topic/nutrition/ iodine-deficiency/ (accessed June 2017).

11. Yusuf HK, Rahman AM, Chowdhury FP et al. (2008) Iodine deficiency disorders in Bangladesh, 2004-05: ten years of iodized salt intervention brings remarkable achievement in lowering goitre and iodine deficiency among children and women. Asia Pac J Clin Nutr 17, 620-628.

12. International Centre for Diarrheal Disease Research, Bangladesh, UNICEF, Global Alliance for Improved Nutrition et al. (2013) National Micronutrients Status Survey 201112: Final Report. Dhaka: Centre for Nutrition and Food Security, icddr,b.

13. Andersson M \& Zimmermann M (2012) Global iodine nutrition: a remarkable leap forward in the past decade. IDD Newsl 40, 1-5.

14. Tran TD, Hetzel B \& Fisher J (2016) Access to iodized salt in 11 low-and lower-middle-income countries: 2000 and 2010. Bull World Health Organ 94, 122-129.

15. De Benoist B \& Clugston G (2002) Eliminating iron deficiency disorders. Bull World Health Organ 80, 341.

16. Bangladesh Bureau of Statistics \& UNICEF (2014) Multiple Indicator Cluster Survey 2012-2013: Progotir pathey. Dhaka: BBS and UNICEF.

17. International Centre for Diarrheal Disease Research, Bangladesh (2015) National Salt Iodization Survey, Bangladesh 2015: Summary Report. Dhaka: Centre for Nutrition and Food Security, icddr,b.

18. Knowles JM, Garrett GS \& Gorstein J et al. (2017) Household coverage with adequately iodized salt varies greatly between countries and by residence type and socioeconomic status within countries: results from 10 national coverage surveys. J Nutr 147, 1004-1014.

19. Ahmed SM, Adams AM, Chowdhury M et al. (2000) Gender, socioeconomic development and health-seeking behaviour in Bangladesh. Soc Sci Med 51, 361-371.

20. Ahmed SM, Chowdhury M \& Bhuiya A (2001) Micro-credit and emotional well-being: experience of poor rural women from Matlab, Bangladesh. World Dev 29, 1957-1966.

21. Kabir ME \& Webb EL (2009) Household and home garden characteristics in southwestern Bangladesh. Agroforestry Syst 75, 129.

22. Killewo J, Anwar I, Bashir I et al. (2006) Perceived delay in healthcare-seeking for episodes of serious illness and its implications for safe motherhood interventions in rural Bangladesh. J Health Popul Nutr 24, 403-412.

23. The DHS Program (2014) Survey Summary. Bangladesh: Standard DHS, 2014. http://www.dhsprogram.com/whatwe-do/survey/survey-display-461.cfm (accessed July 2016). 
24. The DHS Program (2007) Survey Summary. Bangladesh: Standard DHS, 2007. http://www.dhsprogram.com/whatwe-do/survey/survey-display-287.cfm (accessed July 2016).

25. The DHS Program (2011) Survey Summary. Bangladesh: Standard DHS, 2011. http://www.dhsprogram.com/whatwe-do/survey/survey-display-349.cfm (accessed July 2016).

26. Torheim LE, Granli GI, Sidibé CS et al. (2005) Women's iodine status and its determinants in an iodine-deficient area in the Kayes region, Mali. Public Health Nutr 8, 387-394.

27. Wegmüller R, Zimmermann MB, Bühr VG et al. (2006) Development, stability, and sensory testing of microcapsules containing iron, iodine, and vitamin A for use in food fortification. J Food Sci 71, issue 2, S181-S187.

28. Sankar R, Moorthy D, Pandav C et al. (2006) Tracking progress towards sustainable elimination of iodine deficiency disorders in Bihar. Indian J Pediatr 73, 799.

29. Andersson M, Thankachan P, Muthayya S et al. (2008) Dual fortification of salt with iodine and iron: a randomized, double-blind, controlled trial of micronized ferric pyrophosphate and encapsulated ferrous fumarate in southern India. Am J Clin Nutr 88, 1378-1387.

30. Zimmermann MB, Gizak M, Abbott K et al. (2015) Iodine deficiency in pregnant women in Europe. Lancet Diabetes Endocrinol 3, 672-674.

31. Hoddinott J, Maluccio JA, Behrman JR et al. (2008) Effect of a nutrition intervention during early childhood on economic productivity in Guatemalan adults. Lancet 371, 411-416.

32. Girma M, Loha E, Bogale A et al. (2012) Iodine deficiency in primary school children and knowledge of iodine deficiency and iodized salt among caretakers in Hawassa town: Southern Ethiopia. Ethiop J Health Dev 26, 30-35.

33. Tronko M, Kravchenko V, Fink D et al. (2005) Iodine excretion in regions of Ukraine affected by the Chornobyl accident: experience of the Ukrainian-American cohort study of thyroid cancer and other thyroid diseases. Thyroid 15, 1291-1297.

34. Abuye C \& Berhane Y (2007) The goitre rate, its association with reproductive failure, and the knowledge of iodine deficiency disorders (IDD) among women in Ethiopia: cross-section community based study. BMC Public Health 7, 316.

35. Azizi F, Mehran L, Sheikholeslam R et al. (2008) Sustainability of a well-monitored salt iodization program in Iran: marked reduction in goiter prevalence and eventual normalization of urinary iodine concentrations without alteration in iodine content of salt. J Endocrinol Invest 31, 422-431.

36. Erdoğan M, Ağbaht K \& Altunsu T et al. (2009) Current iodine status in Turkey. J Endocrinol Invest 32, 617-622.

37. Saggiorato E, Arecco F, Mussa A et al. (2006) Goiter prevalence and urinary iodine status in urban and rural/ mountain areas of piedmont region. J Endocrinol Invest $\mathbf{2 9}$, 67-73.

38. UNICEF (2013) UNICEF MICS surveys. http://mics.unicef. org/surveys (accessed March 2017).

39. Browne WJ \& Draper D (2006) A comparison of Bayesian and likelihood-based methods for fitting multilevel models. Bayesian Anal 1, 473-514.

40. Hadfield JD (2010) MCMC methods for multi-response generalized linear mixed models: the momcglmm $\mathrm{R}$ package. J Stat Softw 33, 1-22.

41. English S \& Uller T (2016) Does early-life diet affect longevity? A meta-analysis across experimental studies. Biol Lett 12, 20160291.
42. Guo GZ, Sutherland KR, Myers C et al. (2016) Prospective swallowing outcomes after IMRT for oropharyngeal cancer: dosimetric correlations in a population-based cohort. Oral Oncol 61, 135-141.

43. House CM, Jensen K, Rapkin J et al. (2016) Macronutrient balance mediates the growth of sexually selected weapons but not genitalia in male broad-horned beetles. Funct Ecol 30, 769-779.

44. Zimmermann MB \& Andersson M (2012) Assessment of iodine nutrition in populations: past, present, and future. Nutr Rev 70, 553-570.

45. Hetzel BS (2002) Eliminating iodine deficiency disorders: the role of the international council in the global partnership. Bull World Health Organ 80, 410-412.

46. Rydbeck F, Bottai M, Tofail F et al. (2014) Urinary iodine concentrations of pregnant women in rural Bangladesh: a longitudinal study. J Expo Sci Environ Epidemiol 24, 504-509.

47. Rasheed S, Siddique A, Sharmin T et al. (2016) Salt intake and health risk in climate change vulnerable coastal Bangladesh: what role do beliefs and practices play? PLoS One 11, e0152783.

48. Pitt MM, Khandker SR \& Cartwright J (2006) Empowering women with micro finance: evidence from Bangladesh. Econ Dev Cult Change 54, 791-831.

49. Kumar D, Hossain A \& Gope MC (2015) Role of micro credit program in empowering rural women in Bangladesh: a study on Grameen Bank Bangladesh Limited. Asian Bus Rev 3, 114-120.

50. Hawas S, Lemma S, Mengesha S et al. (2016) Proper utilization of adequately iodized salt at house hold level and associated factors in Asella town Arsi zone Ethiopia: a community based cross sectional study. J Food Process Technol 7, 573.

51. Rasheed S, Hanifi MA, Iqbal M et al. (2001) Policy of universal salt iodization in Bangladesh: do coastal people benefit? J Health Popul Nutr 19, 66-72.

52. Sen TK, Das DK, Biswas AB et al. (2010) Limited access to iodized salt among the poor and disadvantaged in NORTH 24 PARGANAS district of West Bengal, India. J Health Popul Nutr 28, 369

53. Kazungu K, Mbakaya C \& Makokha A (2015) Factors contributing to iodide deficiency in coast province of Kenya. Eur J Res Med Sci 3, 45-51

54. Yaye AB, Baraki N \& Endale BS (2016) Availability of adequately iodized salt at household level and associated factors in Dire Dawa, Eastern Ethiopia. Int J Public Health Sci 5, 392-399.

55. Roy R, Chaturvedi M, Agrawal D et al. (2016) Household use of iodized salt in rural area.J Family Med Prim Care 5 , $77-81$.

56. Haji Y, Abdurahmen J \& Paulos W (2017) Knowledge and perception of consumption of iodized salt among food handlers in Southern Ethiopia. Food Nutr Bull 38, 92-102.

57. UNICEF Bangladesh (2009) Media release: Salt iodisation from mill to home. https://www.unicef.org/bangladesh/ media_6143.htm (accessed August 2017).

58. Jabin S (2009) Study on consistency of salt iodization in salt factories. Bangl J Sci Indust Res 44, 225-228.

59. Baulch B (2011) The medium-term impact of the primary education stipend in rural Bangladesh. I Dev Effect $\mathbf{3}$, 243-262.

60. World Health Organization (2016) Salt reduction. http:// www.who.int/en/news-room/fact-sheets/detail/salt-reduction (accessed December 2017). 